\title{
Correction to: Leg length discrepancy and adolescent idiopathic scoliosis: clinical and radiological characteristics
}

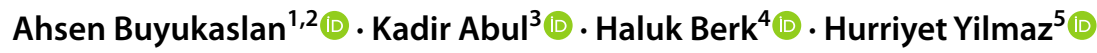

Published online: 26 November 2021

(c) The Author(s), under exclusive licence to Scoliosis Research Society 2021

Correction to: Spine Deformity

https://doi.org/10.1007/s43390-021-00417-0

The original version of this article unfortunately contained a mistake. In Fig. 2 of this article, there was a label reading " $0.7 \mathrm{~mm}$ " instead of " $0.7 \mathrm{~cm}$ ". The figure should have appeared as shown below.

The original article has been corrected.

The original article can be found online at https://doi.org/10.1007/ s43390-021-00417-0.

Ahsen Buyukaslan

ahsen.buyukaslan@gmail.com

1 Formed Healthcare Scoliosis Treatment and Brace Center, Istanbul, Turkey

2 Department of Physical Therapy and Rehabilitation, Graduate School of Health Sciences, Medipol University, Istanbul, Turkey

3 Department of Orthopaedics and Traumatology, Basaksehir Cam and Sakura City Hospital, Istanbul, Turkey

4 Department of Orthopaedics and Traumatology, Faculty of Medicine, Dokuz Eylul University, Izmir, Turkey

5 Department of Physiotherapy and Rehabilitation, Faculty of Health Sciences, Halic University, Istanbul, Turkey 
Fig. 2 C-LLD scoliometer test

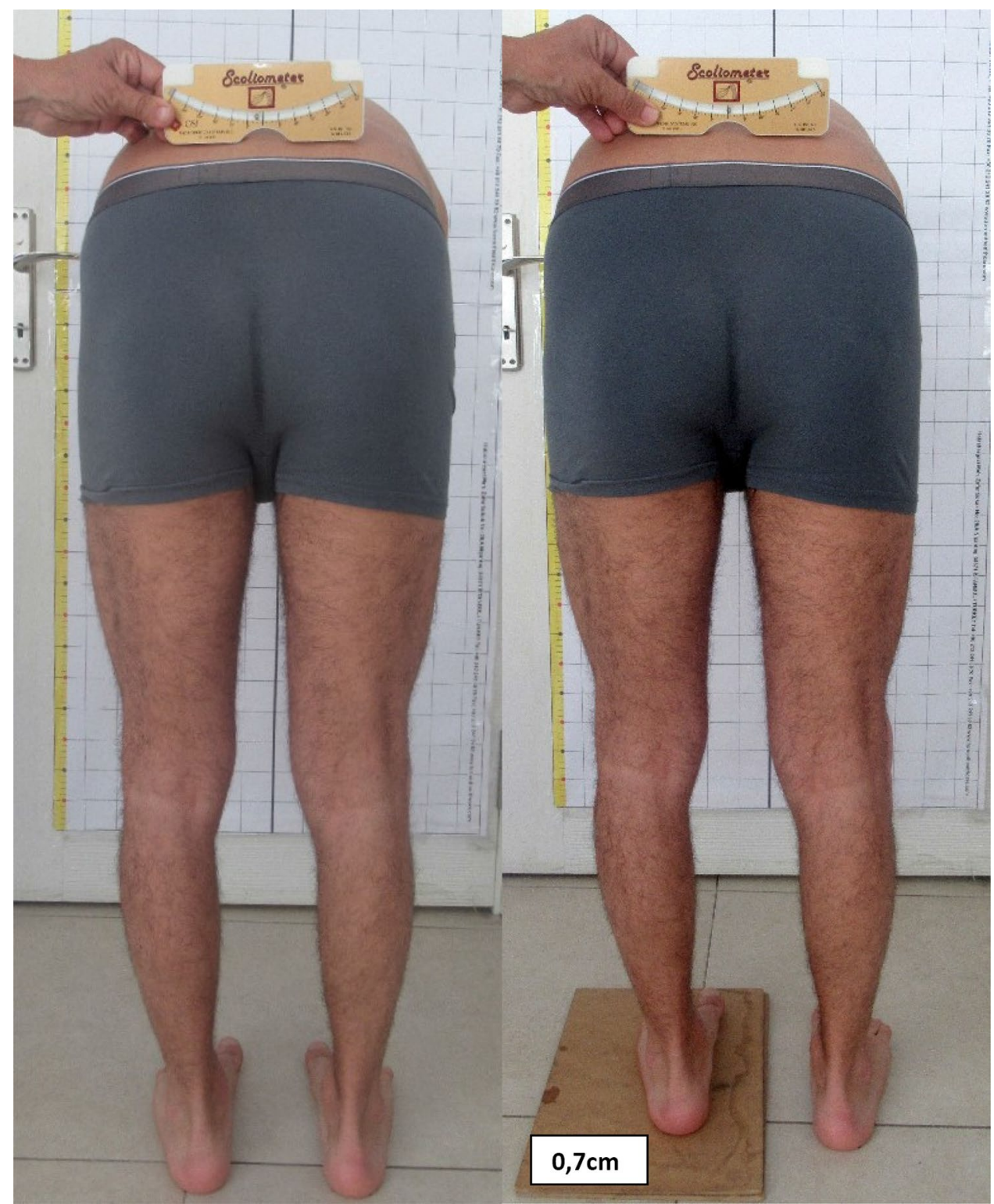

Publisher's Note Springer Nature remains neutral with regard to jurisdictional claims in published maps and institutional affiliations. 